\author{
Rebecca Noone, PhD Candidate \\ Faculty of Information, University of Toronto \\ Toronto, Ontario, Canada
}

\title{
Rerouting Google Maps: drawing- and performance-based methods in action (Paper)
}

\begin{abstract}
The following paper outlines an arts-based research project that uses drawing and performance to critically examine the perceptual conditions generated by locative media, specifically the dominant Google Maps platform. The research is based on a series of wayfinding encounters in four major urban centres-Toronto, ON, New York, NY, London, UK, and Amsterdam, NLduring which the artist-researcher asked passers-by for directions with the additional request the directions be drawn using the instruments provided. The paper considers the street-level behaviours and practices of location-awareness and orientation set against the constructions of trust, seamlessness, and claim to space Google Maps deploys.
\end{abstract}

\section{Introduction}

Over 1 billion people per month use Google Maps to access features such as street maps, panoramic StreetViews, turn-by-turn directions, and traffic conditions. Google estimates that 1 in 3 mobile searches are location-related. The rise in popularity of Google Maps - particularly as a smartphone application - has sparked interest in how human relationships to place are mediated by locative and location-based media (Wilken, \& Goggin, 2015; Farman, 2015; Evans, 2015; de Souza e Silva \& Firth, 2010) as well as how locative media impact the design and infrastructures of cities (McQuire 2016; Mattern 2015; Sassen 2011). As a result, Google Maps is a lens for generating a visual understanding of situatedness based on its real-time mediation of space. Johanna Drucker (2014) argues that dominant graphical forms, often assumed to be neutral, institute and produce visual knowledges. Therefore, to interrogate the perceptual conditions promoted by Google Maps, the paper considers how urban space is visualized at street level in the context of everyday interactions, and how these perceptions and interactions are shaped by Google Maps' affordances. The paper presents the initial findings of my doctoral research project, which brings together drawing and performance-based methods to examine contemporary conditions, behaviours, and practices of location-awareness and orientation in four cities: Toronto, ON, New York, NY, London, UK and Amsterdam NL.

\section{Background}

The research design employs drawing-based visual methods, specifically the drawings of route directions, spontaneously produced in situ, as a means to explore how wayfinding information is visualized and performed. While walking through the four cities, I approached passers-by for directions to nearby sites with the request these directions be drawn. The encounters took place on the thresholds of public information spaces such as outside the library, on the steps of the museum, 
in the public square, by the train station, or through the public park. The recruited informants drew directions using a black pen and a 6"x6" piece of white card stock paper. The encounter yielded two to three types of data: 1) spontaneously drawn route maps from on-the-street interventions; 2) descriptive fieldnotes of the drawing process through observation; 3) recorded semi-structured interviews with selected participants. I collected 220 hand-drawn route maps in Toronto, New York, Amsterdam, and London, combined. I selected the cities as samples of distinctive street layouts such as the orthogonal and grid-like patterns found in Toronto and New York or radial and knotted patterns found in London and Amsterdam. The research design's artistic provocation presents the potential for alternative forms of theory building in information studies, specifically regarding infrastructures and interfaces of wayfinding.
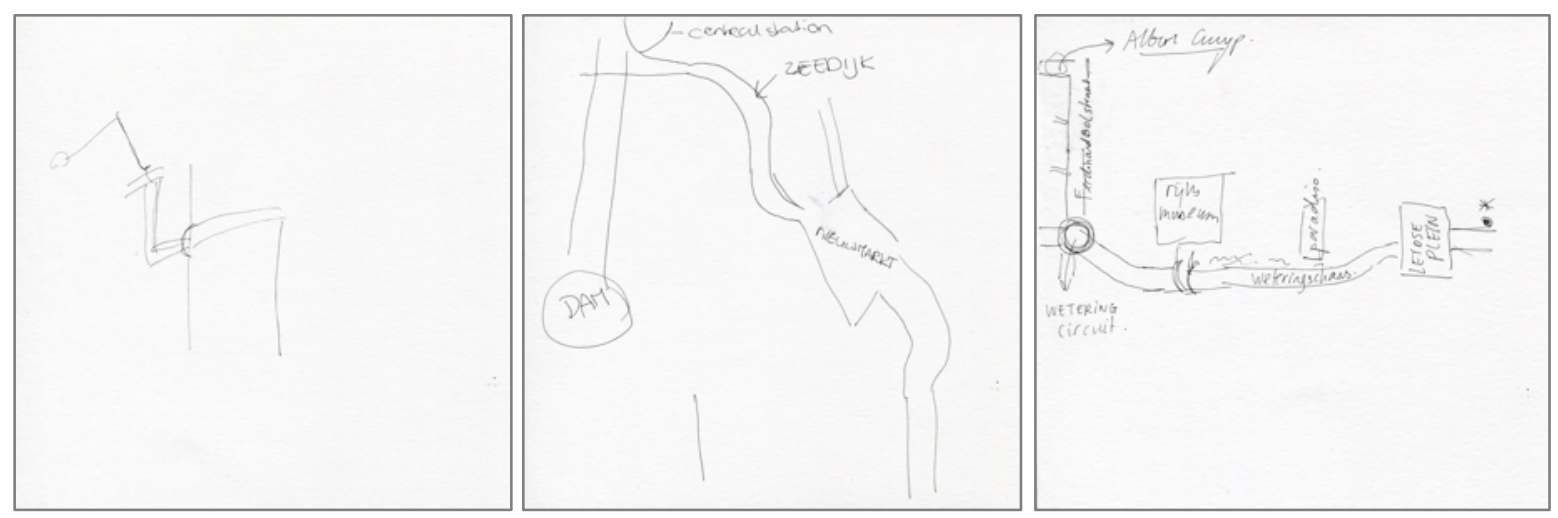

Figure 1: Three examples of hand drawn maps from the Amsterdam dataset

\section{Analysis and Findings}

Over the course of the wayfinding events, Google Maps was repeatedly used to mediate locationawareness, orientation, visualization, and interaction with a stranger. During analysis, I coded for the use of Google Maps across the New York, Toronto, Amsterdam, and London datasets. The mobile device factored into approximately one-third of the encounters across all cities, and 81 of the 220 (37\%) of total encounters. Google Maps was the dominant mapping platform in the dataset accounted for $89 \%$ of encounters that used mobile phones. In both New York and London, Google Maps was used in 20 of the 55 encounters (36\%), in Amsterdam, it was used in 19 times over the 55 encounters (35\%), and in Toronto it was used only 13 times in the 55 encounters $(23 \%)$.

The use of Google Maps was shaped by a recurring set of values. These values are: trust in the information provided by way of Google Maps; seamless integration of Google Maps into everyday experiences; and claims to and on space facilitated by the use of Google Maps. The paper traces Google Maps' discursive configurations of these values and then outlines how the values appear in the dataset. Ultimately, these values bring to bear a specific type of orientation towards the device in urban space and a calibration to that device in the perception of the space. This paper examines the tensions made apparent in the fieldwork between the promises of the values of locative media orientations and the everyday work of being orientated by and calibrated to Google Maps. 
Trust manifested in behaviours of verification that involved checking Google Maps to make sure one's initial directions were correct. Often the informant deferred to Google Maps even if Google Maps provided directions different than one's initial impression. In other cases, Google Maps was used to coordinate understanding of directions by either provided a template to the informant to draw from or as a means to show the suggested route by way of the map interface. There appeared an overall trust in Google among informants who used Google Maps during the encounter. Throughout the dataset, there are no recordings of informants who openly disagreed with the Google Maps route or the Google Maps interface. The trust in the Google Maps ultimately brings attention to the mediation of space through platforms of search and reveal how locative web-based information is not only dominated by Google Maps, but frame a general orientation towards using Google Maps.

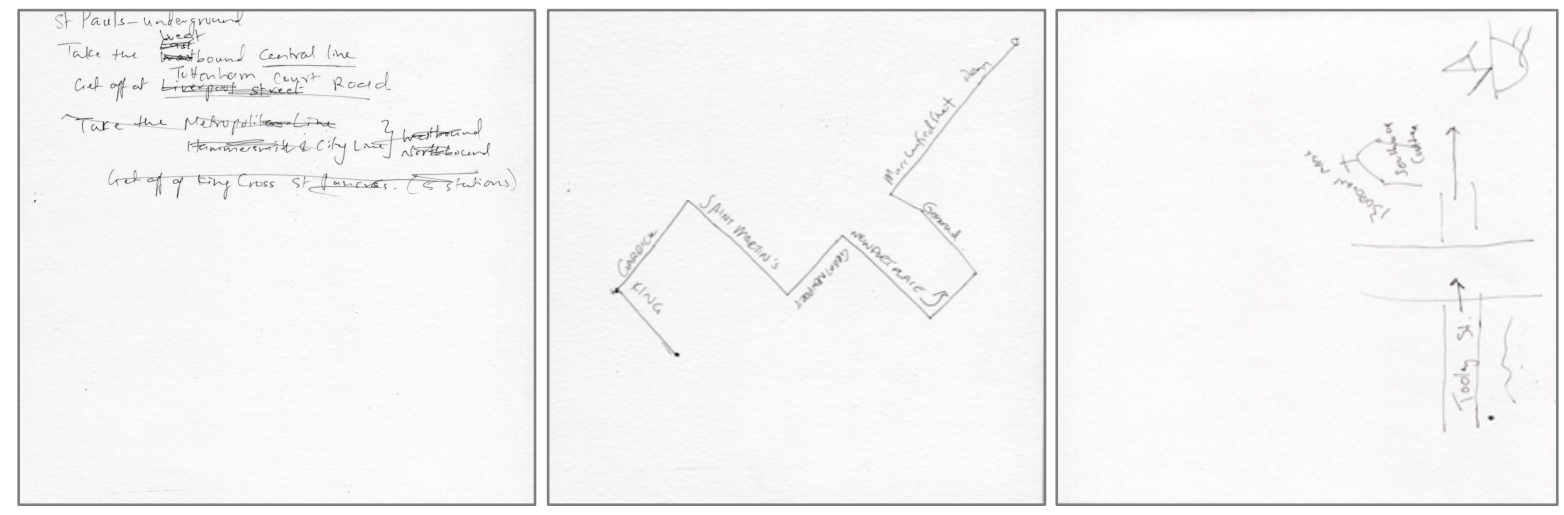

Figure 2: Three examples of hand drawn directions from the London dataset

Google Maps promises a totalizing image of spatial configurations throughout the world, stitched together seamlessly to be read with ease (Presner et al. 2014). The effect of such totalizing is more than simply the offering of a complete picture. It is also the erasure of the lines in between, the borders, and the distinctions, flattening the world to a simple surface (Massey 2005). The data reveals how the promise of seamless integration of Google Maps, from screen to ground, was woven into the encounters, flagging the instances in which the seams were revealed. Such were moments when the potential information flow were interrupted based on issues of failed data connections, hardware failures with frozen screens, batteries dying, failures to load, and spelling errors. In some instances, informants demonstrated difficulty when translating the image on the screen to the street in front of them, or when translating the image on the screen to the act of drawing. The promise of seamlessness became interrupted in instances when the information provided on the screen became difficult to reconcile with the informant's sense of place on the ground. Although Google was deferred to in these moments, the initial step of calibrating information from Google Maps' to a present location was often difficult. 

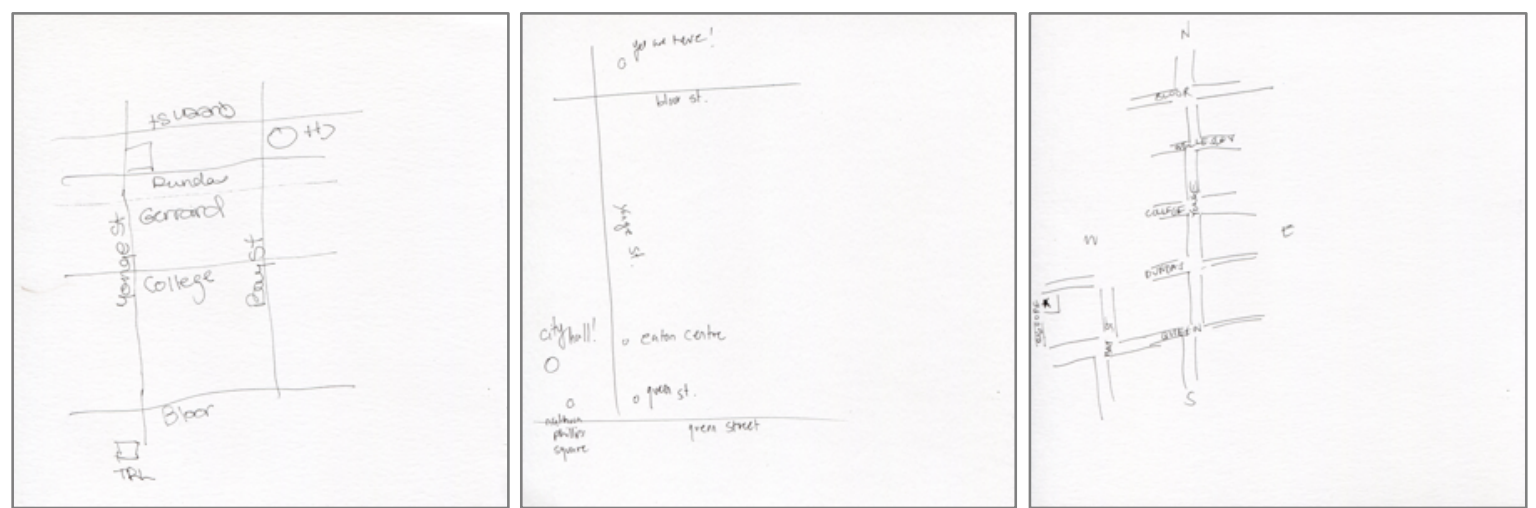

Figure 3: Three examples of hand drawn directions from the Toronto dataset

The confluence of trust and seamlessness resulted in a privileged subject who can freely move through space, unencumbered by the potential of becoming lost. Google Maps becomes the means that enables this sense of unbridled exploration and the confidence to move through the city, thus coded as claims to space. Such claims allowed for informants to give direction while in a part of town they were unfamiliar with, or give directions when they admitted to not knowing the way. The knower of everywhere, and the recalibration of oneself to the map as the savvy borderless citizen emerged in the analysis of the data.
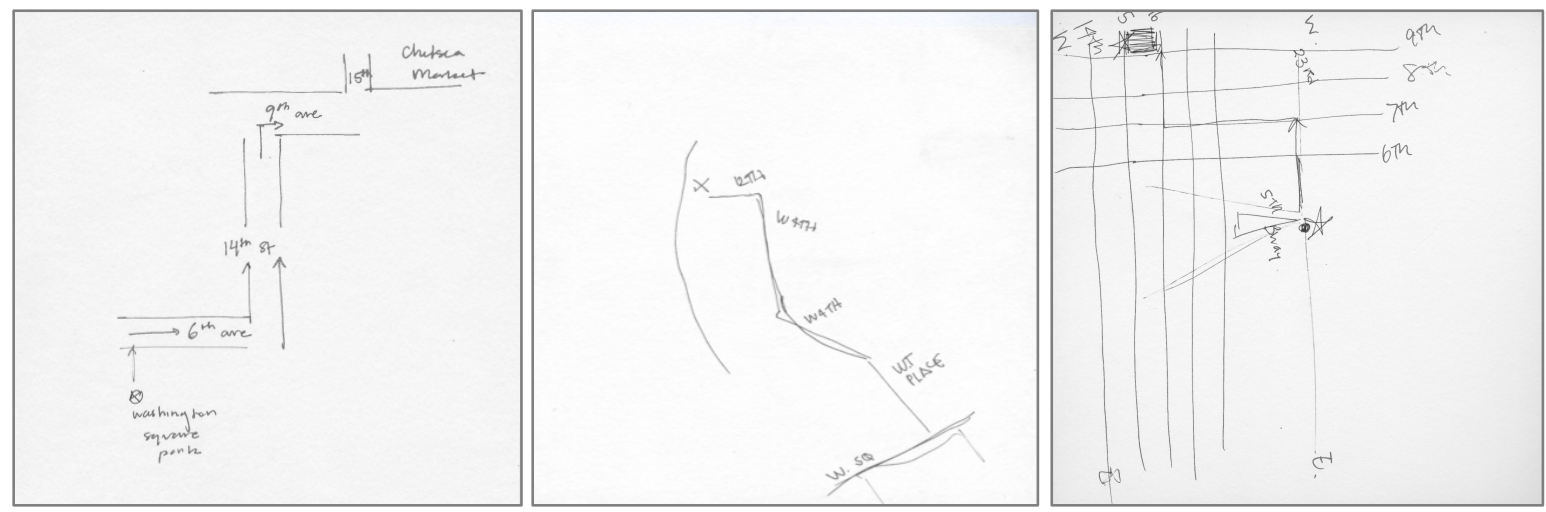

Figure 4: Three examples of hand drawn directions from the New York dataset.

\section{Contributions}

The paper outlines a study that brings together drawing and performance-based practices to explore spatial sense-making and wayfinding strategies within the conditions of digital mapping dominated by Google Maps. The paper examines the sets of values that orient one towards the use Google Maps and are generated by Google Maps- the resulting visualization and spatializations produced. Additionally, readers will be engaged with a creative research design within the visual paradigm of social scientific research that challenges the established authority of Google Maps. The work contributes to the study of spontaneous and ad-hoc drawings (Hartel 
2014; Snyder 2014) in Information Studies situating the drawing event in the thresholds of information spaces and civic sites.

\section{Reference List}

Brouwn, S. (1961). This Way Brouwn. [Collection of drawings from public performances in Amsterdam]. MOMA. New York, NY.

De Souza e Silva, A., \& Frith, J. (2010). Locative mobile social networks: Mapping communication and location in urban spaces. Mobilities, 5(4), 485-505. doi: $10.1080 / 17450101.2010 .510332$

Drucker, J. (2014). Graphesis: Visual forms of knowledge production. Cambridge, MA: Harvard University Press.

Evans, L. (2015). Locative Social Media: Place in the Digital Age. Basingstoke, UK: Palgrave Macmillan.

Farman, J. (2015). Mobile Interface Theory: Embodied Space and Locative Media. New York, NY: Routledge.

Hartel, J. (2014). An arts-informed study of information using the draw-and-write technique. Journal of the American Society for Information Science and Technology, 65(7), 1349-1367. doi: 10.1002/pra2.2015.14505201001

Massey, D.B. (2005). For Space. Thousand Oaks, CA: Sage Publications.

Mattern, S. (2015). Deep Matting the Media City. Minneapolis, MN: University of Minnesota Press.

McQuire, S. (2016). Geomedia: Networked Cities and the Future of Public Spaces. Somerset, NJ: Wiley.

Presner, T., Shepard, D., \& Kawano, Y. (2014). Hypercities: Thick Mapping in the Digital Humanities. Boston, MA: Harvard University Press.

Sassen, S. (2011). Unsettling Topographic Representation. In M. Shepard (Ed.) The Sentient City: Ubiquitous Computing, Architecture, and the Future of Urban Space. Cambridge, MA: MIT Press.

Snyder, J. (2014). Visual Representation of Information as Communicative Practice. Journal of the Association of Information Science and Technology 65(11). 2233-2247. doi: 10.1002/asi.23103

Wilken, R., \& Goggin, G. (2015). Locative Media. New York, NY: Routledge. 